

DE GRUYTER OPEN

\section{Journal of MECHANICAL ENGINEERING - Strojnícky časopis}

VOLUME 66, NO 2, 2016

pp. $79-88$

DOI:10.1515/scjme-2016-0021

\title{
SEISMIC RESISTANCE OF STORAGE TANKS CONTAINING LIQUID IN ACCORDANCE WITH PRINCIPLES OF EUROCODE 8 STANDARD
}

\author{
SIVÝ Martin ${ }^{1}$, MUSIL Miloš ${ }^{1}$ \\ ${ }^{1}$ Slovak University of Technology in Bratislava, Faculty of Mechanical Engineering, Institute of Applied \\ Mechanics and Mechatronics, Nám. Slobody 17,812 31 Bratislava, Slovakia, email: martin.sivy@ stuba.sk
}

\begin{abstract}
Large capacity tanks storing various liquids are important components in distribution and transmission systems. During operation tanks can be subjected to different types of loading. Therefore, maximum attention must be paid to the tank design to capture all possible causes and forms of failures. The article deals with the procedure for seismic resistance of liquid storage tanks which are in accordance with the principles of Eurocode 8 standard. The seismic analysis is performed on flexible (steel) circular vertical ground-supported model of tank containing liquid (water). The main aim is to determine basic seismic characteristics, distributions of hydrodynamic pressure, dynamic properties and response of investigated tank-liquid system subjected to earthquake excitation (El Centro). Seismic analysis and results comparison are carried out on mechanical springmass model (Eurocode 8) and finite element model (ANSYS).
\end{abstract}

KEYWORDS: liquid storage tank, Eurocode 8, spring-mass model, seismic resistance, seismic characteristic, fluid-structure interaction

\section{Introduction}

Liquid storage tanks are widely used in industries mostly for storing water and other liquids with toxic explosive nature or dangerous inflammable substances. In addition to mentioned application, tanks are important components in liquid transmission and distribution systems and they can be installed in nuclear power plants [9, 10] as well. Therefore, satisfactory performance of tanks is crucial for avoiding failures in operation, minimizing tank damages and destructions with the aim to prevent pollution or loss of human lives.

During ordinary operation, large capacity storage tanks can be subjected to static and dynamic loadings $[5,6]$. There are many negative consequences which may be caused by dynamically loaded systems and can take following modes: elastic-plastic buckling of shells due to excessive axial compression taking the form of a bulge called elephant's foot; roof damage caused by sloshing of upper zone of contained liquid with inadequately designed freeboard between liquid surface and roof; sliding of the tank due to friction overcoming caused by increasing base shear, etc. [4]

Presented seismic analysis is performed on a cylindrical vertical steel tank of radius $R$ (6 $\mathrm{m})$, of height $H(6 \mathrm{~m})$ and of wall thickness $t(5 \mathrm{e}-3 \mathrm{~m})$. The storage tank is filled with liquid (water) with free surface height $H_{\mathrm{L}}(5 \mathrm{~m})$. Tank base is fixed to a rigid foundation.

\section{Basic concept}

One of the dynamic loadings, which is of major interest of investigation to many researchers, is a seismic excitation (e.g. example of seismic testing in [12]). Inadequately 
designed or detailed tanks have suffered extensive damage in past earthquakes and have resulted in destructive effects, e.g. breakdown of water supplies, uncontrolled fires with subsequent ignition to adjacent tanks and buildings, clouds of toxic chemicals, etc. Therefore, importance of ensuring safety of such tanks against seismic loads cannot be overemphasized. Dynamic analysis of liquid storage tank is a complex problem involving fluid-structure interaction. Based on numerous analytical, numerical and experimental studies, simple springmass models of tank-liquid system have been developed to evaluate hydrodynamic forces. These spring-mass models (two SDOF systems) for ground-supported tanks are based on work of G. W. Housner [2]. Analytical methods are suitable only for the simplest systems. More about methods and tank-liquid oscillation can be found in [3] as well. For more complex models simple models can be insufficient and inaccurate, therefore, numerical approaches have been developed. The most widely used is the method based on finite elements (FEM).

\subsection{Spring-mass modeling}

When a tank containing liquid with a free surface is subjected to a horizontal seismic excitation, tank walls and liquid are subjected to a horizontal acceleration. The description of the behaviour of investigated tank-liquid system can be advantageously simplified by division of the contained liquid into two parts - impulsive and convective.

The impulsive part represents effects of the lower portion of the liquid which accelerates along with the wall and induces impulsive hydrodynamic pressure on tank wall and similarly on base. It behaves like a rigidly connected mass $m_{\mathrm{ir}}$ to the tank wall at height $h_{\mathrm{i}}$ $\left(h_{\mathrm{i}}{ }^{\prime}\right)$. The convective part in upper region represents the free surface which causes the sloshing effect and it exerts convective hydrodynamic pressure on tank wall and base. It is described by infinite number of convective mass $m_{\mathrm{c} n}$ attached to the tank wall at height $h_{\mathrm{c} n}$ $\left(h_{\mathrm{c} n}\right.$ ') by a spring of stiffness $k_{\mathrm{c} n}$. Each mass in the system corresponds to the effective liquid mass that oscillates in each particular slosh mode. For practical purposes it is acceptable to include only the spring-mass corresponding to the first fundamental mode.

This procedure is valid only for rigid tanks on rigid foundations. Whereas the walls of rigid tanks move in unison with the ground, motion of flexible tanks is different. Flexibility affects the hydrodynamics effects and may increase the seismic characteristics significantly. In mechanical models, flexibility of the tank-liquid system must be taken into account using an additional flexible mass $m_{\mathrm{fr}}$ connected to the tank wall with a spring of appropriate stiffness $k_{\mathrm{f}}$ (Fig. 1) [11].

\subsection{FEM formulation}

In FEM formulation, a tank is modeled by structural elements; liquid is mostly represented by acoustic elements (Euler's formulation). To couple tank and liquid displacements, definition of fluid-structure interaction (FSI) at interface between structural and acoustic elements is required. Therefore, acoustic elements at interface have, in addition to pressure DOF, displacement DOFs as well (Fig. 2).

To assume the fluid-structure interaction, additional terms are added to the equations of motion and their matrix form can be written as follows 

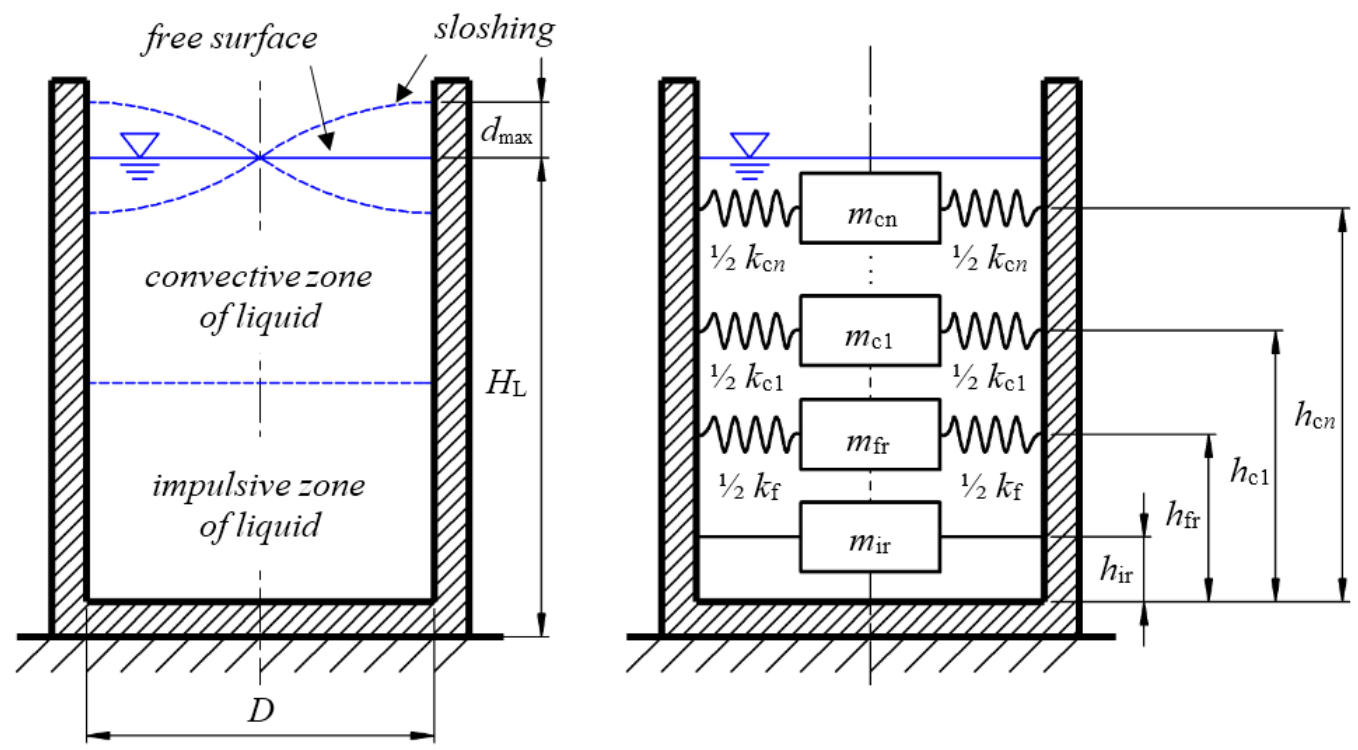

Fig. 1 Spring-mass equivalent mechanical model [11]
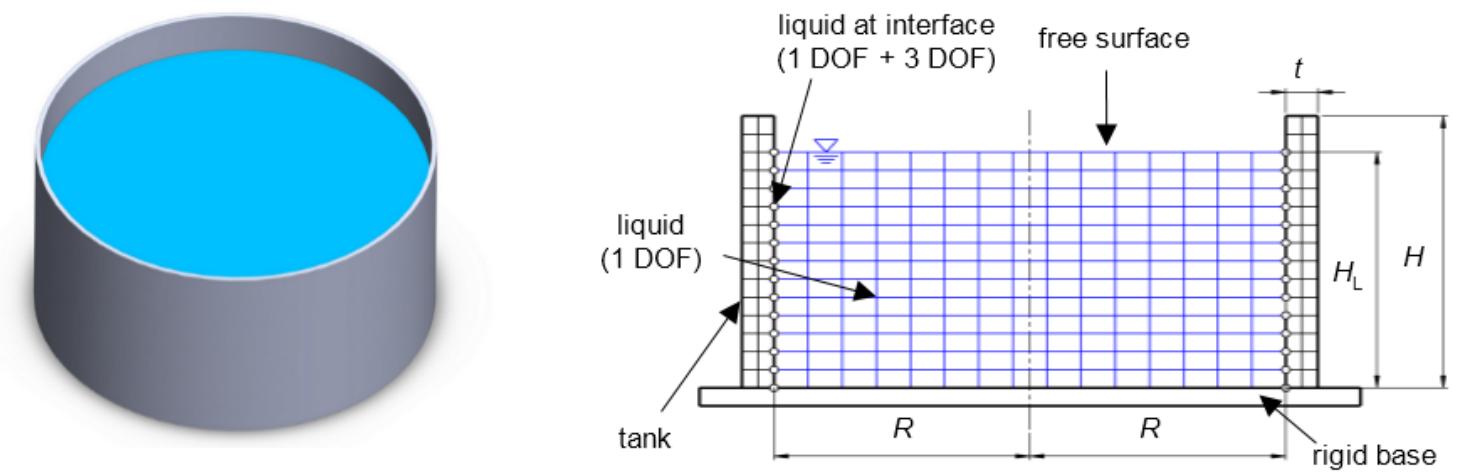

Fig. 2 Fluid-structure interaction

$\left[\begin{array}{cc}\mathbf{M}_{\mathbf{s}} & 0 \\ \rho_{\mathrm{L}} \mathbf{R}^{\mathrm{T}} & \mathbf{M}_{\mathbf{f}}\end{array}\right]\left[\begin{array}{c}\ddot{\mathbf{u}} \\ \ddot{\mathbf{p}}\end{array}\right]+\left[\begin{array}{cc}\mathbf{C}_{\mathbf{s}} & 0 \\ 0 & \mathbf{C}_{\mathbf{f}}\end{array}\right]\left[\begin{array}{c}\dot{\mathbf{u}} \\ \dot{\mathbf{p}}\end{array}\right]+\left[\begin{array}{cc}\mathbf{K}_{\mathbf{s}} & -\mathbf{R} \\ 0 & \mathbf{K}_{\mathbf{f}}\end{array}\right]\left[\begin{array}{l}\mathbf{u} \\ \mathbf{p}\end{array}\right]=\left[\begin{array}{c}\mathbf{f}_{\mathbf{s}} \\ \mathbf{f}_{\mathbf{f}}\end{array}\right]$

where $\mathbf{M}_{\mathbf{s}}$ and $\mathbf{M}_{\mathbf{f}}$ are the structural and fluid mass matrix respectively; $\mathbf{C s}$ and $\mathbf{C}_{\mathbf{f}}$ represent structural and acoustic damping matrix respectively; $\mathbf{K}_{\mathbf{s}}$ and $\mathbf{K}_{\mathbf{f}}$ are the structural and fluid stiffness matrix respectively; $\mathbf{f}_{\boldsymbol{s}}$ and $\mathbf{f}_{\mathbf{f}}$ are the vectors of applied structural and fluid loads respectively; $\mathbf{u}$ is a vector of unknown nodal displacements and $\mathbf{p}$ is a vector of unknown nodal acoustic pressures. $\mathbf{R}$ stands for the coupling matrix.

\section{Procedure for seismic analysis}

The aim of the past investigation has been to develop methods to evaluate earthquake resistance of liquid storage tanks and to provide codes for engineers engaged in the construction of these systems. Some of the proposed procedures and recommendations have been underlain in international (AWWA, ACI, API, Eurocode 8, etc.) or national standards (PNM34080183) [7].

The article is focused on application of principles introduced in Eurocode 8 standard (Design of structures for earthquake resistance) and its fourth part (Silos, tanks and pipelines). This standard specifies principles and application rules for the seismic design of the structural aspects of facilities composed of above-ground and buried pipeline systems and of storage

Volume 66, No. 2, (2016) C2016 SjF STU Bratislava 
tanks of different types and uses, as well as for independent items, such as for example water towers serving a specific purpose [1].

\subsection{Hydrodynamic pressure}

According to Eurocode 8 standard, hydrodynamic pressure of the flexible tanks is expressed as the sum of three contributions: rigid impulsive, flexible and convective. The flexibility of the tank wall has a direct impact on the impulsive liquid that experiences accelerations that may be greater than peak ground acceleration (flexible component varies with response acceleration whilst the rigid impulsive component varies only with a ground acceleration) [7]. The dynamic coupling between the flexible and convective components of hydrodynamic pressure is weak (large differences between natural frequencies of the sloshing liquid and the tank-liquid system) which allows determining the second component independently of the others. The rigid impulsive and the convective components remain unaffected by wall flexibility. The flexible pressure distribution depends on the modes of oscillation of tank-liquid system [1].

The spatial-temporal distributions of rigid impulsive, flexible and convective components of pressure are given respectively by

$$
\begin{gathered}
p_{\mathrm{i}}(\xi, \varsigma, \theta, t)=C_{\mathrm{i}}(\xi, \varsigma) \rho_{\mathrm{L}} H_{\mathrm{L}} A_{\mathrm{g}}(t) \cos \theta \\
p_{\mathrm{f}}(\varsigma, \theta, t)=\rho_{\mathrm{L}} H_{\mathrm{L}} \psi \cos \theta \sum_{n=0}^{\infty} d_{n} \cos \left(v_{n} \varsigma\right) A_{\mathrm{f} n}(t) \\
p_{\mathrm{c}}(\xi, \varsigma, \theta, t)=\rho_{\mathrm{L}} \sum_{n=0}^{\infty} \psi_{n} \cosh \left(\lambda_{n} \gamma \varsigma\right) J_{1}\left(\lambda_{n} \xi\right) \cos \theta A_{\mathrm{c} n}(t)
\end{gathered}
$$

where $A_{\mathrm{g}}(t)$ denotes the ground acceleration time-history, $A_{\mathrm{c} n}(t)$ is the acceleration timehistory of SDOF oscillator with natural frequency $\omega_{\mathrm{c} n}$ and $A_{\mathrm{f} n}(t)$ is the pseudo-acceleration function with the natural frequency of the tank-liquid system. The rest of the parameters are introduced in [1]. Fig. 3 presents the maximum contributions of hydrodynamic pressure along the free surface height of the investigated model.
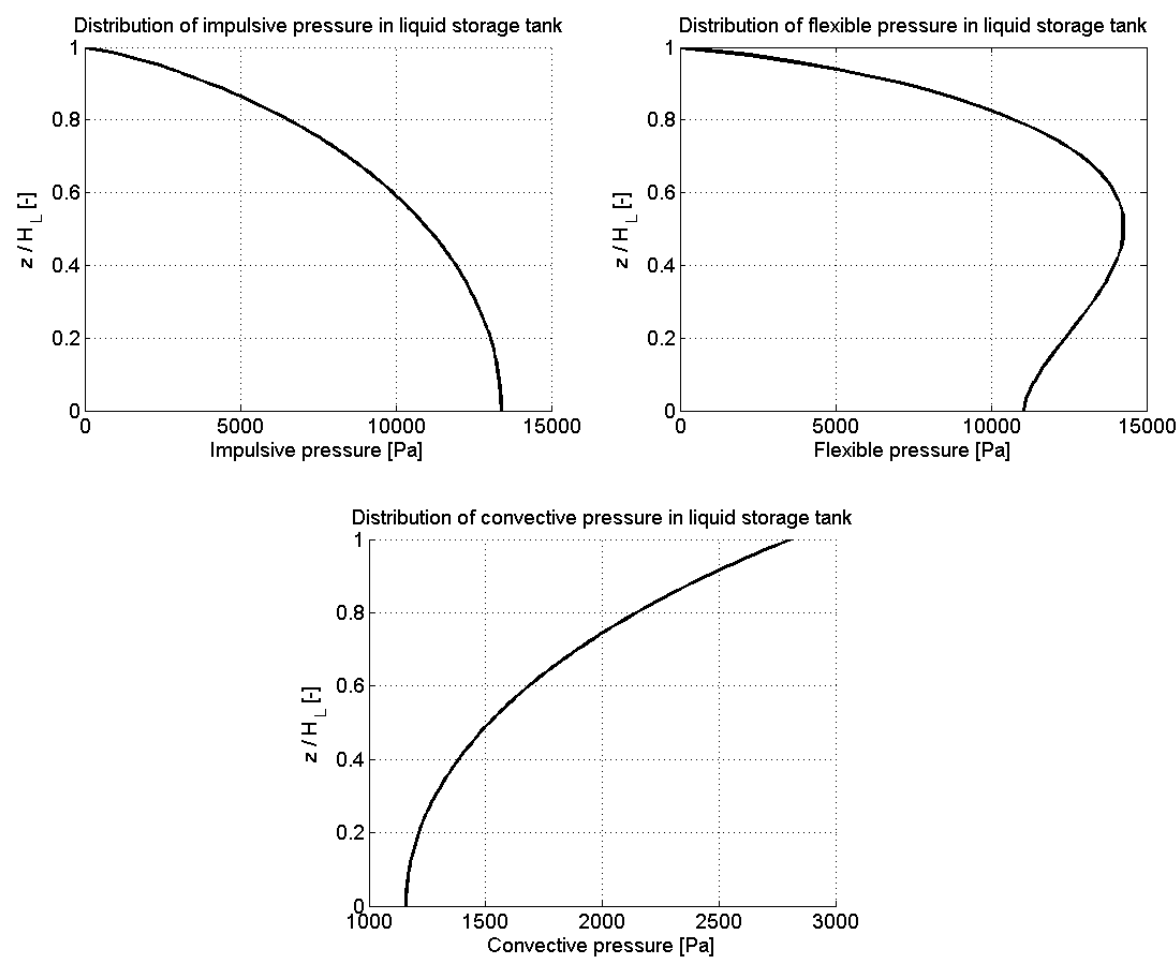

Fig. 3 Maximum contributions of hydrodynamic pressure along the tank height 


\subsection{Basic seismic characteristics}

The total base shear is defined as the total dynamic force exerted by the liquid on the tank wall and can be defined as the sum of the impulsive and convective contributions

$$
Q=\left(m_{\mathrm{i}}+m_{\mathrm{w}}+m_{\mathrm{r}}\right) S_{\mathrm{e}}\left(f_{\mathrm{i}}\right)+m_{\mathrm{c}} S_{\mathrm{e}}\left(f_{\mathrm{c}}\right)
$$

where $m_{\mathrm{w}}$ and $m_{\mathrm{r}}$ represent the wall and the roof mass, $S_{\mathrm{e}}\left(f_{\mathrm{i}}\right)$ and $S_{\mathrm{e}}\left(f_{\mathrm{c}}\right)$ are spectral accelerations, obtained from the elastic response spectrum respectively.

The hydrodynamic overturning moment $M$ immediately above the tank bottom includes only the components of the pressure on the walls. The hydrodynamic overturning moment $M$ ' immediately below the tank bottom includes the components of the pressure on the tank walls and of those on the tank bottom. Both types of overturning moments are defined as the sum of impulsive and convective contributions and may be determined as

$$
\begin{gathered}
M=\left(m_{\mathrm{i}} h_{\mathrm{i}}+m_{\mathrm{w}} h_{\mathrm{w}}+m_{\mathrm{r}} h_{\mathrm{r}}\right) S_{\mathrm{e}}\left(f_{\mathrm{i}}\right)+m_{\mathrm{c}} h_{\mathrm{c}} S_{\mathrm{e}}\left(f_{\mathrm{c}}\right) \\
M^{\prime}=\left(m_{\mathrm{i}} h_{\mathrm{i}}^{\prime}+m_{\mathrm{w}} h_{\mathrm{w}}+m_{\mathrm{r}} h_{\mathrm{r}}\right) S_{\mathrm{e}}\left(f_{\mathrm{i}}\right)+m_{\mathrm{c}} h_{\mathrm{c}}^{\prime} S_{\mathrm{e}}\left(f_{\mathrm{c}}\right)
\end{gathered}
$$

where $h_{\mathrm{w}}$ and $h_{\mathrm{r}}$ are the heights of wall and roof centers of gravity respectively.

\subsection{Natural frequencies and respective modes of oscillation}

The tank-liquid system is modeled by two SDOF systems, one corresponding to the impulsive component and the other corresponding to the convective component. Responses are combined by taking their numerical sum. The natural frequencies of both responses are defined as follows

$$
f_{\mathrm{i}}=\frac{1}{C_{\mathrm{i}}} \frac{\sqrt{t / R} \sqrt{E}}{\sqrt{\rho_{\mathrm{L}}} H_{\mathrm{L}}} \quad f_{\mathrm{c}}=\frac{1}{C_{\mathrm{c}} \sqrt{R}}
$$

where $\rho_{\mathrm{L}}$ is the density of the liquid, $E$ is a modulus of elasticity of the tank material. $C_{\mathrm{i}}$ and $C_{\mathrm{c}}$ represent coefficients for their respective slenderness $H_{\mathrm{L}} / R$. Dependency of these coefficients on slenderness parameter $\gamma$ is shown in Fig. 4.

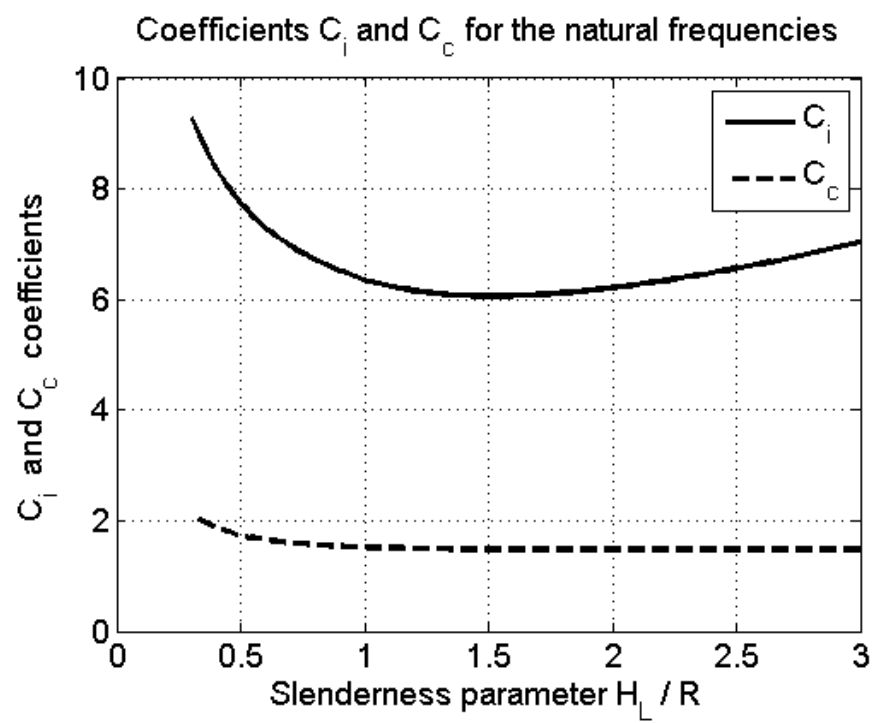

Fig. $4 \mathrm{Ci}$ and $\mathrm{Cc}$ coefficients for the natural frequencies [4]

When liquid oscillates in unison with the tank, an impulsive frequency occurs. It represents the most unfavourable response to the system which behaves like a cantilever beam with a 
mass equivalent to the mass of the tank and liquid [7]. The response of the investigated system (Fig. 5) occurs at $12.49 \mathrm{~Hz}$ (in ANSYS $12.45 \mathrm{~Hz}$ ).


Fig. 5 Mode of oscillation of the impulsive mass

Sloshing effects of the convective liquid are the another unfavourable response to the tank-liquid system which may rupture the roof or the top of tank. Sloshing is described by infinite antisymmetric mode shapes. Fig. 6 presents the first three modes of oscillation of the investigated model which occur at the frequencies listed in Table 1. They are compared with analytical approach introduced in Eurocode 8 (spring-mass model).

Table 1 Comparison of the natural frequencies considering the first convective mass

\begin{tabular}{ccc}
\hline & Eurocode 8 & ANSYS \\
\hline 1. & $0.2636 \mathrm{~Hz}$ & $0.2637 \mathrm{~Hz}$ \\
2. & $0.4698 \mathrm{~Hz}$ & $0.4714 \mathrm{~Hz}$ \\
3. & $0.5946 \mathrm{~Hz}$ & $0.5998 \mathrm{~Hz}$ \\
\hline
\end{tabular}

\subsection{Response to seismic excitation}

When evaluating seismic resistance computationally, various methods which differ in their application, can be employed. They are quasi-static method, spectrum response and integration of motion equations [8].

In the case that a structure, subject to ground spectra of rigid character with the first resonant frequency greater than $35 \mathrm{~Hz}$, the equations of motion can be reduced to static equations.

If the seismic loading is loaded linearly with proportional damping of the system that does not correlate with the seismic excitation in each direction and the first resonant frequency is lower than $35 \mathrm{~Hz}$, then the spectral response method can be employed.

The method of integrating the equations of motion is the most general and can be used for both previous mentioned cases. It is used, if the structure shows nonlinear behaviour, is nonproportionally damped or seismic excitation from different directions shows significant correlation. It is also used when a measured time-dependent excitation signal is considered. 
Due to time-dependent seismic excitation, time-history analysis is applied. This analysis uses the method of integrating the equations of motion and the solution is in time domain (e.g. the time-varying displacements, strains, stresses, etc.).

1.
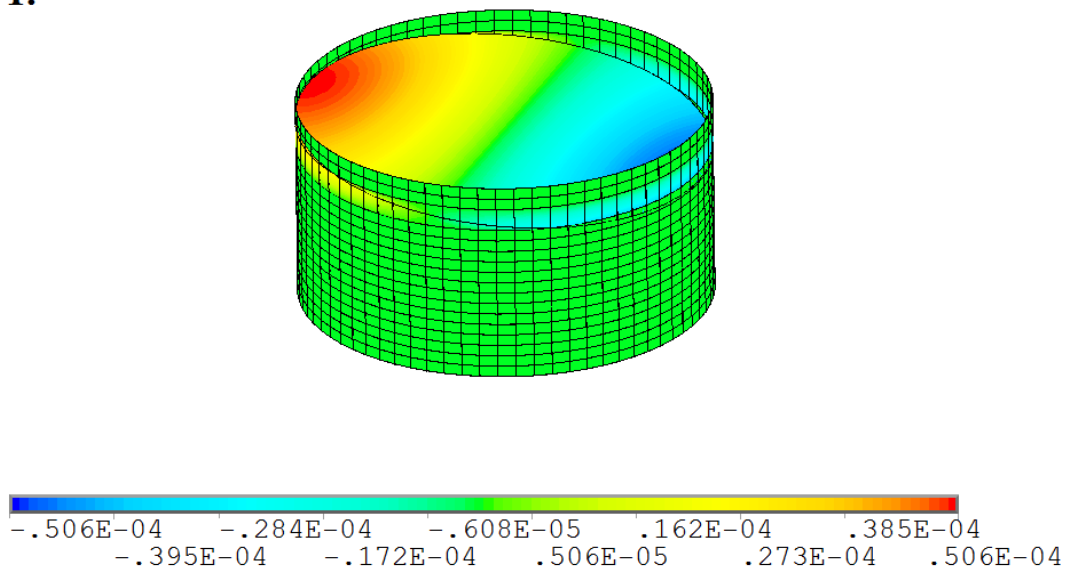

2.
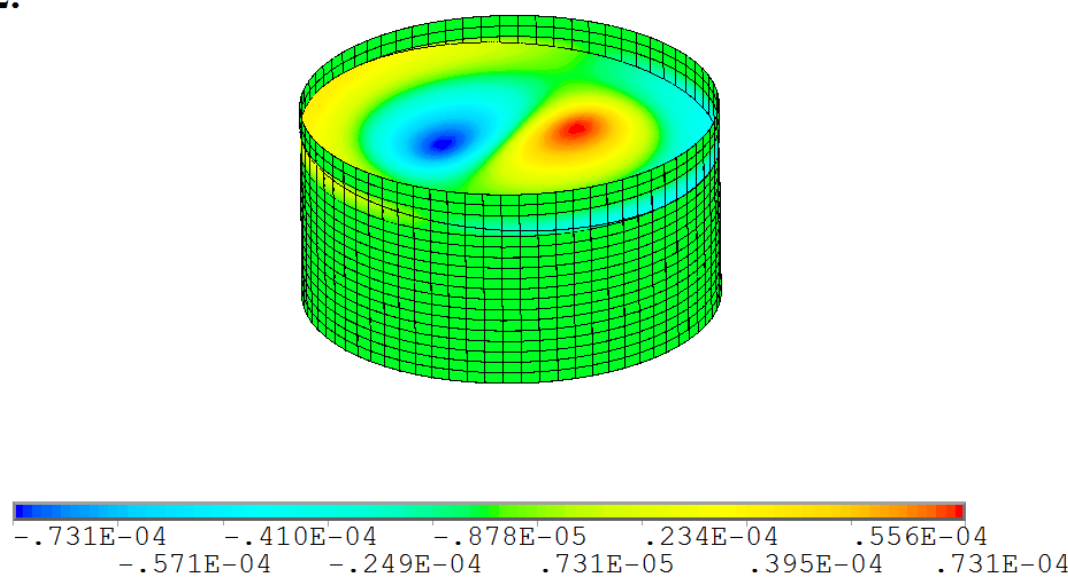

3.

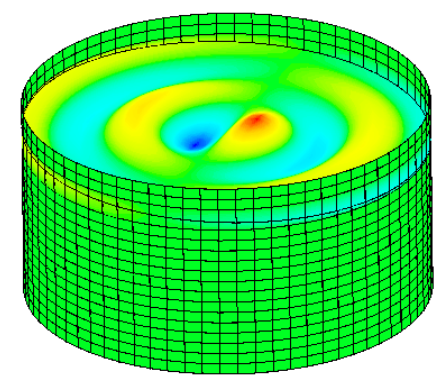

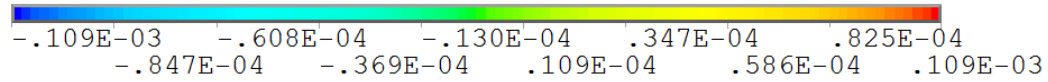

Fig. 6 First three modes of oscillation of the convective mass

As a seismic input, acceleration time-history of the El Centro earthquake (California, 1940) with PGA $3.417 \mathrm{~m} / \mathrm{sec}^{2}$ at $2.14 \mathrm{sec}$ is used. This loading is applied to the tank-liquid system in $x$-direction. Displacements at every time step are the outputs of the analysis. Fig. 7 presents 
the maximum response of investigated model to the seismic excitation. This response with peak value of $1.275 \mathrm{e}-3 \mathrm{~m}$ occurs at $5.00 \mathrm{sec}$.
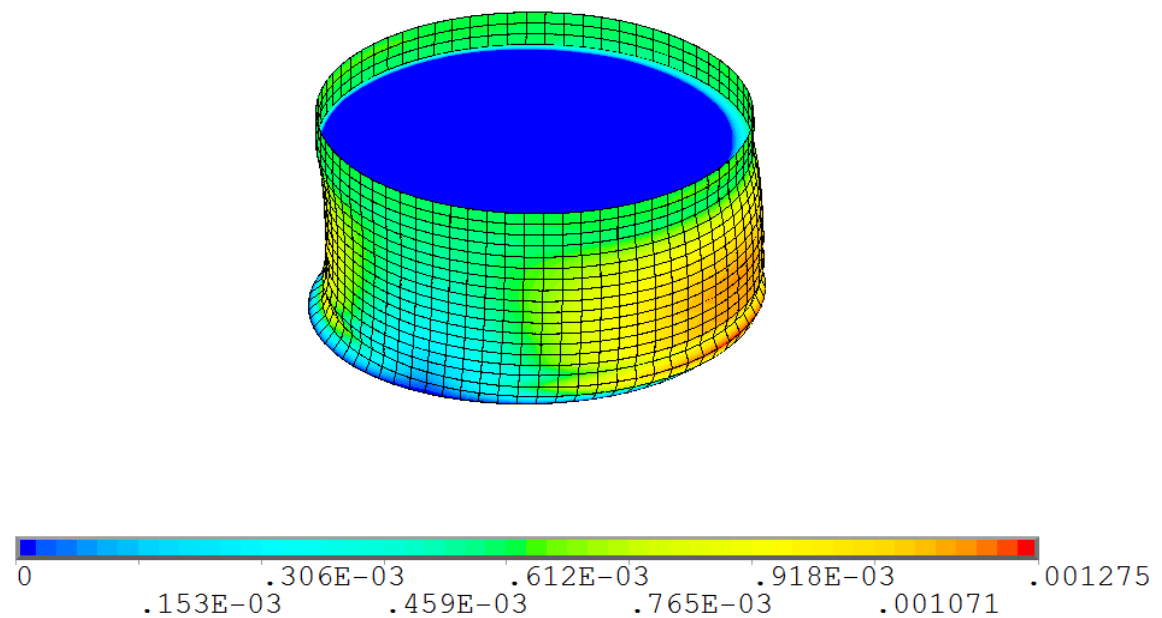

Fig. 7 Response of liquid storage tank to seismic excitation [8]

In addition to investigation of seismic response to tank-liquid system, attention should be paid to the computation of maximum sloshing wave height since ruptures of the tank top may occur. To withstand roof damage caused by sloshing, a sufficient freeboard must be provided. The sloshing wave height may be given from the following expression

$$
d(r, \theta, t)=R \sum_{n=1}^{\infty} \frac{2}{\lambda_{n}^{2}-1} \frac{J_{1}\left(\lambda_{n} \frac{r}{R}\right)}{J_{1}\left(\lambda_{n}\right)} \frac{S_{\mathrm{e}}\left(f_{\mathrm{c} n}\right)}{g} \cos \theta
$$

where $S_{\mathrm{e}}\left(f_{\mathrm{c} n}\right)$ is the elastic spectral acceleration at a convective frequency; $J_{1}$ is a Bessel function of the first kind and $\lambda_{n}$ are values for which the first derivative of $J_{1}$ is zero.

a)



b)

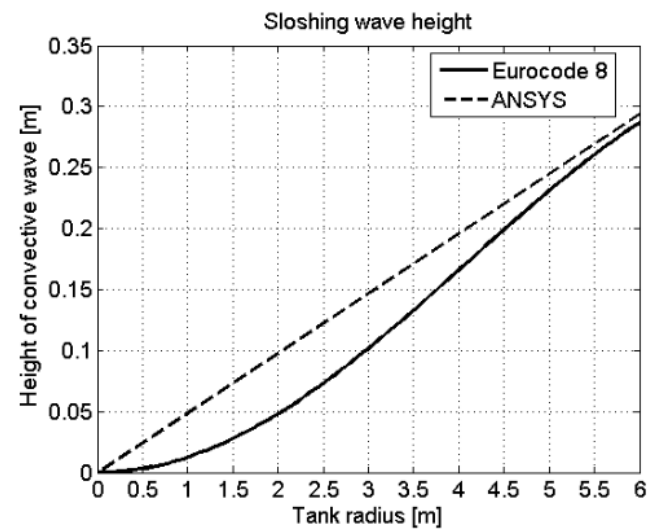

Fig. 8 Free surface vertical displacements along tank radius

In Fig. 8, free surface displacements along tank radius with absolute maximum value at the interface for response acceleration at first convective frequency is presented. Using (6) maximum vertical displacement is $0.2866 \mathrm{~m}$ and $0.2911 \mathrm{~m}$ using ANSYS (Fig. 8a). Computed maximum sloshing heights represent the good conformity, however, in contrast to Eurocode 8, free surface displacements along tank radius of FE model increase linearly due to linear element formulation (Fig. 8b). These differences along tank radius are, however, 
unessential. Maximum wave displacements at tank wall are crucial with respect to standard requirements.

\section{Conclusions}

The aim of this article was to perform a seismic analysis on the model of circular vertical ground-supported liquid storage tank according to Eurocode 8. Applying of principles introduced in the standard, basic seismic characteristics, components of hydrodynamic pressure, dynamic properties of tank-liquid system were calculated.

Due to the different responses (wall flexibility), rigid and flexible tanks should be appropriately distinguished. This difference is significant especially when investigating the hydrodynamic pressure and tank oscillation. On the other hand, response of the convective liquid mass and its contribution to hydrodynamic pressure are not affected by wall flexibility. The flexible component of the hydrodynamic pressure has a tendency to shift a peak ordinate from the base to the top.

The situation, when liquid oscillates in unison with the tank, represents an unfavourable response to the system. Due to the sloshing effect, it is necessary to determine the sloshing wave height to prevent ruptures and fluid spilling.

Finite element model was used for comparison of dynamic properties of investigated system and for computation of the response to seismic loading using appropriate method. The results between each solution represented good conformity. Seismic analysis is one of the analyses which should be carried out to provide satisfactory performance of tanks, especially in earthquake prone regions.

\section{Acknowledgement}

The article was supported by the STU Grant scheme for Support of Young Researchers and by the grant from Grant Agency of VEGA no. 1/0742/15 entitled "Analysis for Seismic Resistance of Liquid Storage Tanks with Nonlinear and Time-Dependent Parameters".

\section{REFERENCES}

[1] Eurocode 8 - Design of Structures for Earthquakes Resistance: Part 4 - Silos, tanks and pipelines, European Committee for Standardization, Brussels, 1998.

[2] G. W. Housner, Earthquake Pressures on Fluid Containers, California Institute of Technology, California, 1954.

[3] A. R. Ibrahim, Liquid Sloshing Dynamics Theory and Applications, Cambridge University Press, 2005.

[4] P. K. Malhotra, T. Wenk, M. Wieland, Simple Procedure for Seismic Analysis of Liquid Storage Tanks, in: Structural Engineering, IABSE, Vol. 10, 3 (2010).

[5] M. Musil, O. Záhorec, Contribution to Parametrical Identification, Machine Vibration, 2 (1993), pp. 243-247.

[6] M. Musil, Základy dynamiky strojov s Matlabom, Nakladatel'stvo STU, Bratislava, 2013.

[7] M. Sivý, M. Musil, Procedure for Seismic Analysis of Liquid Storage Tanks using FEM Approach and Analytical Models, in: Advances in Mechanism Design II: Proceedings of the XII International Conference on the Theory of Machines and Mechanisms, Springer, 2017, pp. 213-219.

[8] M. Sivý, M. Musil, Comparison of Time-History and Spectrum Analysis of Flexible Liquid Storage Tank for Seismic Excitation using FEM Approach, in: Noise and 
Vibration in Practice: Peer-reviewed Scientific Proceedings, Nakladatel'stvo STU, Bratislava, 2016, pp. 115-118.

[9] J. Úradníček, A. Horniaková, M. Musil, J. Keníž, An Applied Research of Seismic and Vibration Resistance of the Equipment with Assessment of Seismic and Vibration Effects, in: EuroNoise 2015, Proceedings of the 10th European Congress and Exposition on Noise Control Engineering, Maastricht, Netherlands, 2015.

[10] J. Úradníček, M. Musil, L. Ploskuňáková, A. Suchal, Evaluation of the Seismic Resistance of the Cooling Device in the Nuclear Power Plant, in: ERIN 2013, 7th International Conference for Young Researchers and PhD. Students, Nakladatel'stvo STU, Bratislava, 2013.

[11]A. S. Veletsos, Seismic Response and Design of Liquid Storage Tanks. Guidelines for the Seismic Design of Oil and Gas Pipeline Systems, Technical Council on Lifeline Earthquake Engineering (ASCE), 1984.

[12] S. Žiaran, M. Čekan, O. Chlebo, M. Musil, Analysis of Seismic Response on the Excitation of Support Structures, in: Inter-Noise 2014, Proceedings of the 43rd International Congress on Noise Control Engineering, Toowong DC, The Australian Acoustical Society, 2014.

[13] R. Jančo, L. Écsi, P. Élesztös. FSW Numerical Simulation of Aluminium Plates by SYSWELD - part 1. Strojnicky časopis - Journal of Mechanical engineering, 66. p. 